\title{
PENGARUH TERAPI REFLEKSI ALAT PIJAT KAYU (APIYU) DENGAN MINYAK ZAITUN TERHADAP TEKANAN DARAH PADA PENDERITA HIPERTENSI
}

\author{
Windy Enola Putri ${ }^{1}$, Wasisto Utomo ${ }^{2}$, Gamya Tri Utami ${ }^{3}$ \\ ${ }^{1,2,3}$ Fakultas Keperawatan Universitas Riau \\ Fakultas Keperawatan Universitas Riau Jalan Pattimura No 9 \\ Gedung G Pekanbaru Riau Kode Pos 28131 Indonesia \\ Email: windyenola38@gmail.com
}

\begin{abstract}
Abstrak
Hipertensi adalah suatu keadaan ketika tekanan darah di pembuluh darah meningkat secara kronis. Penelitian ini bertujuan untuk mengetahui pengaruh terapi refleksi alat pijat kayu (APIYU) dengan minyak zaitun terhadap tekanan darah pada pasien dengan hipertensi. Metode yang digunakan pada penelitian adalah quasy experiment dengan pendekatan non-equivalent control group. Pengambilan sampel menggunakan purposive sampling dengan jumlah 34 responden adalah kelompok eksperimen dan kelompok kontrol. Pada kelompok eksperimen diberikan terapi refleksi Alat Pijat Kayu (APIYU) dengan minyak zaitun selama 30 menit dalam waktu 6 hari. Pada kelompok kontrol tidak diberikan intervensi. Kedua kelompok tetap mengkonsumsi obat hipertensi. Pengukuran tekanan darah dilakukan sebelum dan setelah diberikan terapi. Alat ukur yang digunakan lembar observasi dan sphygmomanometer digital. Analisis yang digunakan adalah dependent $t$ test dan independent $t$ test. Hasil penelitian menunjukkan terjadi penurunan, rata-rata tekanan darah sistolik pada kelompok eksperimen pre test yaitu 149,26 $\mathrm{mmHg}$ dan post test yaitu 145,44 mmHg. Rata-rata tekanan darah diastolik pre test $92,55 \mathrm{mmHg}$ dan post test $91,30 \mathrm{mmHg}$. Hasil uji statistik menunjukkan penurunan tekanan darah secara signifikan pada kelompok eksperimen dengan $p$ value $0,000(p<0,05)$. Hasil uji statistik mean tekanan darah sistol sesudah intervensi pada kelompok eksperimen dan kontrol diperoleh $p$ value $0,000(p<0,05)$ dan mean tekanan darah diastol sesudah intervensi pada kelompok eksperimen dan kontrol diperoleh $p$ value $0,014(p<0,05)$. Penelitian ini menyimpulkan bahwa terapi refleksi Alat Pijat Kayu (APIYU) dengan minyak zaitun dapat menurunkan tekanan darah.
\end{abstract}

Kata Kunci: Hipertensi, Minyak Zaitun, Pijat Refleksi, Tekanan darah.

\section{Abstract}

Hypertension is a condition when blood pressure in blood vessels increases chronically. The purpose of this study was to determine the effect of reflection therapy on wooden massage devices (APIYU) with olive oil for blood pressure in patients with hypertension. The method of the research was quasy experiment with nonequivalent control group approach. Sampling uses purposive sampling with a total of 34 respondents, there are the experimental group and the control group. In the experimental group were given a reflection therapy of wooden massage equipment (APIYU) with olive oil for 30 minutes within 6 days. The control groups were not given any intervention. Both groups continued to take hypertension medication. Blood pressure measurement is carried out before and after therapy. The measuring instrument used was the observation sheet and sphygmomanometer digital. The analysis used was dependent $t$ test and independent $t$ test. The results showed a decrease, mean in pre test systolic blood pressure in the experimental group of 149.26 $\mathrm{mmHg}$ and mean post test of $145.44 \mathrm{mmHg}$. Mean blood pressure diastolic pre test $92.55 \mathrm{mmHg}$ and post test $91.30 \mathrm{mmHg}$. The statistical test results showed a significant decrease in blood pressure in the experimental group with $p$ value $0.000(p<0.05)$. The result of the mean statistical test for systolic blood pressure after intervention in the experimental and control group with $p$ value $0.000(p<0.05)$ and mean diastolic blood pressure after intervention in the experimental and control group with $p$ value 0.014 ( $p<$ 0.05). The conclusion: the results showed that the reflection therapy of wooden massage devices (APIYU) with olive oil can reduce blood pressure.

Keywords: Blood Pressure, Hypertension, Olive Oil, Reflexology. 
Windy Enola Putri ${ }^{1}$, Wasisto Utomo ${ }^{2}$, Gamya Tri Utami ${ }^{3}$, Pengaruh Terapi Refleksi Alat Pijat Kayu (APIYU) dengan Minyak Zaitun terhadap Tekanan Darah pada Penderita Hipertensi

\section{PENDAHULUAN}

Hipertensi adalah suatu keadaan ketika tekanan darah di pembuluh darah meningkat secara kronis. Hal tersebut dapat terjadi karena jantung bekerja lebih keras memompa darah untuk memenuhi kebutuhan oksigen dan nutrisi tubuh. Penyakit ini biasa mengganggu organ-organ lain, seperti jantung dan ginjal (Riskesdas Nasional, 2013). Hipertensi adalah suatu kondisi kronis ketika tekanan darah pada dinding arteri atau pembuluh darah mengalami peningkatan (Anies, 2018).

Hipertensi dikelompokkan menjadi dua bagian yaitu hipertensi primer dan sekunder. Hipertensi primer terjadi pada 90\% kasus. Faktor risiko yang dapat menyebabkan seseorang terkena hipertensi terdiri dari faktor yang dapat dikontrol dan faktor yang tidak dapat dikontrol (Rawasiah, 2014).

Prevalensi hipertensi di Indonesia berdasarkan data Hasil Riset Kesehatan Dasar pada tahun 2013 terdapat 20,8\% di wilayah Sumatera. Penelitian dari Alikin (2014) menyatakan bahwa salah satu penyakit yang menjadi perhatian dunia adalah hipertensi. Persentase hipertensi di Provinsi Riau yaitu sebanyak 20,9\%. Prevalensi hipertensi tertinggi yaitu berada di daerah Kampar, Pekanbaru, dan Dumai (Riskesdas, 2013).

Data dari Dinas Kesehatan Kota Pekanbaru (2017) didapatkan data hipertensi tertinggi, yaitu terdapat di dua Puskesmas yang berada di Kota Pekanbaru. Puskesmas tertinggi pertama yaitu Puskesmas Payung
Sekaki sebanyak 3.708 orang yang memiliki penyakit hipertensi dan tertinggi kedua yaitu Puskesmas Lima Puluh Kota sebanyak 3.196 orang. Data sekunder didapatkan dari Puskesmas Payung Sekaki Kota Pekanbaru (2018) bahwa kasus hipertensi tertinggi terdapat pada Kelurahan Labuh Baru Timur (Wilayah Kerja Puskesmas Kecamatan Payung Sekaki) sebanyak 636 orang.

Pengobatan hipertensi dapat dilakukan secara farmakologis dan non farmakologis. Pengobatan farmakologis adalah pengobatan yang dilakukan dengan menggunakan obatobatan. Pengobatan farmakologis memiliki efek samping yang dapat memperburuk penyakit atau efek fatal lainnya. Salah satu alternatif yang tepat dalam menurunkan tekanan darah tanpa ketergantungan obat, efek sampingnya yaitu dengan menggunakan terapi non farmakologis (Wirakusumah, 2012).

Pengobatan non farmakologis dapat menurukan tekanan darah pada penderita hipertensi bisa dilakukan dengan berbagai cara yaitu dengan teknik mengurangi stres, mengurangi konsumsi alkohol dan rokok, olahraga atau aktivitas fisik, akupresur dan teknik relaksasi. Teknik relaksasi dapat menurunkan denyut jantung dengan cara yaitu menghambat respons stres saraf simpatif (Corwin, 2009).

Teknik relaksasi mempunyai pengaruh yang sama dengan obat antihipertensi dalam menurunkan tekanan darah seseorang. Terapi konservatif dan terapi komplementer 
merupakan pilihan yang bisa dipertimbangkan untuk meminimalisirkan efek samping yang ditimbulkan dari pengobatan farmakologis. Pengobatan komplementer adalah pengobatan yang meliputi promotif, preventif, kuratif dan rehabilitatif yang dilakukan oleh tenaga kesehatan dengan keamanan dan efektivitas tinggi salah satunya adalah terapi pijat refleksi (Mills, 2012).

Terapi pijat refleksi merupakan salah satu pengobatan terapi komplementer non farmakologis (Putra, 2014). Pijat atau memijat artinya melakukan penekanan pada bagian tubuh tertentu dengan menggunakan jari atau alat bantu sehingga peredaran darah menjadi lancar dan mengurangi tekanan. Pemijatan yang dilakukan dapat membuat asupan oksigen ke otak menjadi lancar (Hayuaji, 2016). Manfaat dari pijat refleksi ini adalah untuk mengurangi rasa sakit pada tubuh, meningkatkan daya tahan tubuh, meringankan gejala migrain. Teknik dasar yang sering dipakai dalam pijat refleksi adalah dengan cara teknik merambatkan ibu jari, memutar tangan dan kaki, serta teknik menekan dan menahan (Wahyuni, 2014).

Hasil penelitian yang dilakukan oleh Rezky, Hasneli, dan Hasanah (2015) tentang pengaruh terapi pijat refleksi kaki terhadap tekanan darah pada penderita hipertensi primer yang dilakukan kedua kelompok tekanan darah sistolik dan diastolik sangat efektif. Hasil penelitian yang diperkuat oleh Nugroho (2012), menunjukkan bahwa pijat refleksi kaki lebih efektif dibandingkan hipnoterapi dalam menurunkan tekanan darah. Penelitian ini juga diperkuat oleh Zunaidi (2014) menunjukkan bahwa pijat refleksi terhadap tekanan darah pada penderita hipertensi sangat berpengaruh.

Pengobatan hipertensi dengan minyak zaitun dapat menyembuhkan berbagai penyakit diantaranya kolesterol, jantung, stroke, kanker payudara, kanker rahim, luka lambung dan radang persendian (Bagaskoro, 2012). Minyak zaitun dapat menurunkan Low Density Lipoprotein (LDL) dalam darah dan meningkatkan High Density Lipoprotein (HDL) yang berfungsi untuk memperlancar sirkulasi darah serta untuk menurunkan tekanan darah (Kurniawan, 2013).

Minyak zaitun mengandung tinggi polifenol. Polifenol adalah suatu senyawa kimia alami sebagai antioksidan yang memberikan perlindungan kepada sel-sel dari radikal bebas dan mencegah resiko penyakit jantung (Setiadi, 2013). Polifenol memberikan efek vasodilatasi dalam pembuluh darah melalui peningkatan Nitric Oxide Syntase (NOS). Kandungan polifenol dan lemak tak jenuh dalam minyak zaitun extra virgin dapat membantu memperlancar aliran darah. Hal ini dapat menjadi alternatif pengobatan hipertensi sebagai terapi komplementer pendamping pengobatan secara farmakologis. Kandungan minyak zaitun mampu menembus kulit ke lapisan epidermis, karena memiliki efek analgesik dan relaksan sehingga dapat mudah menyebar ke tubuh yang lain (Supriadi, 2013). 
Windy Enola Putri ${ }^{1}$, Wasisto Utomo ${ }^{2}$, Gamya Tri Utami ${ }^{3}$, Pengaruh Terapi Refleksi Alat Pijat Kayu (APIYU) dengan Minyak Zaitun terhadap Tekanan Darah pada Penderita Hipertensi

Hasil penelitian oleh Wijayanto (2016) bahwa pengaruh terapi massage dengan minyak aromaterapi terhadap tekanan darah pasien hipertensi primer sangat efektif menurunkan tekanan darah sistolik dibandingkan dengan terapi masase menggunakan minyak VCO. Penelitian yang dilakukan oleh Kamal, Widada dan Kurniawan (2013) menunjukkan terapi komplementer bekam dan minyak zaitun berpengaruh terhadap penurunan tekanan darah pada penderita hipertensi sangat efektif.

Studi pendahuluan yang dilakukan oleh peneliti pada tanggal 29 oktober 2018 di Puskesmas Payung Sekaki dengan mewawancarai 10 orang pasien hipertensi. 6 dari 10 penderita mengatakan tidak mengetahui tentang pijat refleksi dengan menggunakan minyak zaitun yang memiliki manfaat terhadap tekanan darah. Penderita tersebut mengatakan bahwa ia mengkonsumsi obat antihipertensi yang diberikan dokter dan mengkonsumsi beberapa obat tradisional seperti jus timun, dan bawang putih untuk menurunkan tekanan darah, tetapi pengobatan tersebut kurang efektif.

Tujuan penelitian ini dapat memberikan informasi bagi masyarakat dan dijadikan intervensi bagi penderita hipertensi untuk melakukan pijat refleksi.

\section{METODE PENELITIAN}

Penelitian ini dilaksanakan di wilayah kerja Puskesmas Payung Sekaki Kota
Pekanbaru di Kelurahan Labuh Baru Timur yang dimulai dari bulan April sampai Mei 2019. Penelitian ini merupakan penelitian kuantitatif dengan metode Quasi Experiment dengan rancangan Non-Equivalent Control Group with Pre-test and Post-test.

Populasi dari penelitian ini adalah penderita hipertensi yang berada di Kelurahan Labuh Baru Timur (Wilayah Kerja Puskesmas Payung Sekaki Kota Pekanbaru) dengan kriteria inklusi: penderita yang menderita hipertensi primer atau esensial dengan derajat 1 yaitu tekanan darah 140/90 mmHg - 159/90 mmHg dengan rentang usia yaitu 45-59 tahun. Sampel penelitian berjumlah 34 orang dibagi menjadi 2 kelompok yaitu 17 kelompok eksperimen dan 17 kelompok kontrol.

Alat ukur yang digunakan adalah Sphygmomanometer digital sedangkan pijat refleksi adalah Alat Pijat Kayu (APIYU II) yang dibuat oleh Hasneli (2015). Analisis univariat yang digunakan untuk mendapatkan gambaran tentang distribusi karakteristik responden berupa data kategorik disajikan dalam distribusi frekuensi dan persentase dari variabel usia, jenis kelamin, IMT, tingkat pendidikan, suku, status pekerjaan, nama obat dan waktu konsumsi. Analisis bivariat yang digunakan yaitu uji $\mathrm{t}$ dependent dan uji $\mathrm{t}$ independent. Penelitian ini menggunakan uji normalitas menggunakan rasio Skewness. 


\section{HASIL PENELITIAN}

\section{A. Karakteristik Responden}

Analisis univariat digunakan untuk mendapatkan data karakteristik responden dan mean tekanan darah sistolik dan diastolik pre test dan post-test pada kelompok eksperimen dan kelompok kontrol.

Tabel 1

Distribusi karakteristik responden

\begin{tabular}{|c|c|c|c|c|c|c|c|}
\hline \multirow[t]{2}{*}{$\begin{array}{c}\text { Karakteri } \\
\text { stik }\end{array}$} & \multicolumn{2}{|c|}{$\begin{array}{c}\text { Kelompok } \\
\text { Eksperimen } \\
(\mathbf{n}=17)\end{array}$} & \multicolumn{2}{|c|}{$\begin{array}{l}\text { Kelompok } \\
\text { Kontrol } \\
(n=17)\end{array}$} & \multicolumn{2}{|c|}{ Jumlah } & \multirow[t]{2}{*}{$\begin{array}{c}\text { P value } \\
\text { Uji } \\
\text { Homoge } \\
\text { nitas }\end{array}$} \\
\hline & $\mathbf{n}$ & $\%$ & $\mathbf{n}$ & $\%$ & $\mathbf{n}$ & $\%$ & \\
\hline \multicolumn{8}{|l|}{ Usia (th): } \\
\hline $36-45$ & 1 & 5,9 & 1 & 5,9 & 2 & 5,9 & \multirow{3}{*}{0,954} \\
\hline $46-55$ & 8 & 47,1 & 11 & 64,7 & 19 & 55,9 & \\
\hline $56-65$ & 8 & 47,1 & 5 & 29,4 & 13 & 38,2 & \\
\hline \multicolumn{8}{|c|}{ Jenis Kelamin } \\
\hline Perempuan & 28 & 82,4 & 13 & 76,5 & 28 & 82,4 & \multirow[b]{2}{*}{0,656} \\
\hline Laki-laki & 6 & 17,6 & 4 & 23,5 & 6 & 17,6 & \\
\hline \multicolumn{8}{|l|}{ IMT: } \\
\hline Kurus & 1 & 2,9 & - & - & 1 & 2,9 & \multirow{3}{*}{1,000} \\
\hline Normal & 32 & 94,1 & 16 & 94,1 & 32 & 94,1 & \\
\hline Gemuk & 1 & 2,9 & 1 & 5,9 & 1 & 2,9 & \\
\hline \multicolumn{8}{|l|}{ Pendidiksn } \\
\hline $\begin{array}{l}\text { Tidak } \\
\text { Sekolah }\end{array}$ & - & - & - & - & - & - & \multirow{5}{*}{0,734} \\
\hline SD & 4 & 11,8 & - & - & 4 & 11,8 & \\
\hline SMP & 7 & 20,6 & 4 & 23,5 & 7 & 20,8 & \\
\hline SMA & 19 & 55,9 & 12 & 70,6 & 19 & 55,9 & \\
\hline PT & 4 & 11,8 & 1 & 5,9 & 4 & 11,8 & \\
\hline \multicolumn{8}{|l|}{ Suku: } \\
\hline Minang & 9 & 52,9 & 7 & 41,2 & 16 & 47,1 & \multirow{4}{*}{0,954} \\
\hline Jawa & 2 & 11,8 & 7 & 41,2 & 9 & 26,5 & \\
\hline Melayu & 5 & 29,4 & 2 & 11,8 & 7 & 20,6 & \\
\hline Batak & 1 & 5,9 & 1 & 5,9 & 2 & 5,9 & \\
\hline \multicolumn{8}{|l|}{ Pekerjaan } \\
\hline Bekerja & 3 & 17,6 & 3 & 17,6 & 6 & 17,6 & \multirow[b]{2}{*}{1,000} \\
\hline $\begin{array}{l}\text { Tidak } \\
\text { bekerja }\end{array}$ & 14 & 82,4 & 14 & 82,4 & 28 & 82,4 & \\
\hline \multicolumn{8}{|l|}{ Merokok } \\
\hline Iya & - & - & - & - & - & - & \multirow{2}{*}{1,000} \\
\hline Tidak & 17 & 100 & 17 & 100 & 34 & 100 & \\
\hline \multicolumn{8}{|l|}{ Obat: } \\
\hline Captopril & 4 & 23,5 & 1 & 5,9 & 5 & 14,7 & \multirow{2}{*}{0,103} \\
\hline Amlodipin & 13 & 76,5 & 16 & 94,1 & 29 & 85,3 & \\
\hline \multicolumn{8}{|l|}{ Waktu: } \\
\hline Pagi & 3 & 17,6 & - & - & 3 & 8,8 & \multirow{2}{*}{0,103} \\
\hline Malam & 14 & 82,4 & 17 & 100 & 31 & 91,2 & \\
\hline
\end{tabular}

Tabel 1 menunjukkan bahwa sebagian besar penderita hipertensi dalam penelitian ini berada pada rentang usia 46-55 tahun sebanyak 55,9\%, mayoritas berjenis kelamin perempuan sebanyak $84,9 \%$, tingkat pendidikan mayoritas responden adalah tamatan SMA sebanyak 55,9\%, suku responden adalah Minang yaitu sebanyak 47,1\%, kategori pekerjaan mayoritas responden tidak bekerja sebanyak 82,4\%, kategori merokok aalah tidak merokok sebanyak $100 \%$, mayoritas obat yang dikonsumsi adalah amlodipine sebanyak $85,3 \%$, dan mayoritas waktu konsumsi obat yaitu malam hari sebanyak 91,2\%.

Uji homogenitas didapatkan hasil semua karakteristik responden yang terdiri dari usia, jenis kelamin, IMT, tingkat pendidikan, suku, status pekerjaan, kebiasaan merokok, nama obat dan waktu konsumsi pada kelompok eksperimen dan kontrol adalah homogen dengan $p$ value $>\alpha(0,05)$.

Tabel 2

Distribusi rata-rata tekanan darah sistolik dan diastolik sebelum dan sesudah intervensi pada kelompok eksperimen dan kelompok kontrol

\begin{tabular}{|c|c|c|c|c|c|c|}
\hline & Variabel & $\mathbf{N}$ & Mean & SD & Min & Max \\
\hline \multirow{6}{*}{$\begin{array}{l}\text { Pre } \\
\text { test }\end{array}$} & \multicolumn{6}{|c|}{ Eksperimen } \\
\hline & Sistol & 17 & 149,26 & 3,64 & 145,0 & 155,1 \\
\hline & Diastol & 17 & 92,55 & 1,60 & 90,33 & 95,17 \\
\hline & \multicolumn{6}{|c|}{ Kontrol } \\
\hline & Sistol & 17 & 150,83 & 2,86 & 145,33 & 155,83 \\
\hline & Diastol & 17 & 92,71 & 1,53 & 90,67 & 96,33 \\
\hline \multicolumn{7}{|c|}{ Eksperimen } \\
\hline \multirow{5}{*}{$\begin{array}{r}\text { Post } \\
\text { test }\end{array}$} & Sistol & 17 & 145,44 & 3,60 & 141,00 & 151,17 \\
\hline & Diastol & 17 & 91,30 & 1,90 & 88,84 & 94,67 \\
\hline & Kontro & & & & & \\
\hline & Sistol & 17 & 150,60 & 2,69 & 145,67 & 155,67 \\
\hline & Diastol & 17 & 90,20 & 1,43 & 90,17 & 95,33 \\
\hline
\end{tabular}

Tabel 2 menunjukkan bahwa rata-rata tekanan darah sistolik dan diastolik kelompok eksperimen sebelum intervensi adalah 149,26 $\mathrm{mmHg}$ dan 92,55 mmHg dan kelompok kontrol 150,83 mmHg dan 92,71 mmHg. Ratarata tekanan darah sistolik dan diastolik pada kelompok eksperimen sesudah intervensi 
Windy Enola Putri ${ }^{1}$, Wasisto Utomo ${ }^{2}$, Gamya Tri Utami ${ }^{3}$, Pengaruh Terapi Refleksi Alat Pijat Kayu (APIYU) dengan Minyak Zaitun terhadap Tekanan Darah pada Penderita Hipertensi

adalah $145,44 \mathrm{mmHg}$ dan $91,30 \mathrm{mmHg}$ dan kelompok kontrol 150,60 $\mathrm{mmHg}$ dan 90,20 $\mathrm{mmHg}$.

\section{B. Tekanan Darah Kelompok Eksperimen dan Kontrol}

Analisis bivariat digunakan melihat perbedaan tekanan darah sistolik dan diastolik pada kelompok eksperimen dan kelompok kontrol serta melihat pengaruh terapi pijat refleksi kaki terhadap tekanan darah.

Tabel 3

Rata-rata tekanan darah sistolik dan diastolik sebelum intervensi pada kelompok eksperimen dan kelompok kontrol

\begin{tabular}{lcccc}
\hline \multicolumn{1}{c}{ Variabel } & Mean & SD & N & p value \\
\hline Sistolik & & & & \\
Eksperimen & 149,26 & 3,64 & 17 & 0,135 \\
Kontrol & 150,83 & 2,86 & 17 & \\
\hline Diastolik & & & & \\
Eksperimen & 92,55 & 1,60 & 17 & 0,768 \\
Kontrol & 92,71 & 1,53 & 17 & \\
\hline
\end{tabular}

Tabel 4 menunjukkan uji homogenitas rata-rata tekanan darah sistolik dan diastolik pre test pada kelompok eksperimen dan kelompok kontrol. Hasil uji homogenitas dengan menggunakan uji Levene test didapatkan bahwa rata-rata tekanan darah sistolik kelompok eksperimen dan kelompok kontrol adalah homogen dengan $p$ value 0,135 $(p>\alpha)$, sedangkan rata-rata tekanan darah diastolik pada kelompok eksperimen dan kontrol diketahui homogen dengan $p$ value $0,768(p>\alpha)$.
Tabel 4

Perbedaan rata-rata tekanan darah sistolik dan diastolik sebelum dan sesudah intervensi pada kelompok eksperimen

\begin{tabular}{|c|c|c|c|c|c|}
\hline $\begin{array}{c}\text { Tekanan } \\
\text { Darah }\end{array}$ & Mean & SD & $\mathbf{S E}$ & $\mathbf{N}$ & $\begin{array}{c}p \\
\text { value }\end{array}$ \\
\hline a. Sistolik & & & & & \multirow{3}{*}{0,000} \\
\hline Pre test & 149,26 & 3,64 & 0,88 & 17 & \\
\hline Post test & 145,44 & 3,60 & 0,87 & 17 & \\
\hline \multicolumn{6}{|l|}{ b. Diastolik } \\
\hline Pre test & 92,55 & 1,60 & 0,38 & 17 & \multirow[t]{2}{*}{0,000} \\
\hline Post test & 91,30 & 1,90 & 0,46 & 17 & \\
\hline
\end{tabular}

Uji dependent pada kelompok pada kelompok eksperimen diperoleh $p$ value 0,000 $(p<\alpha)$, hasl ini berarti bahwa ada perbedaan yang signifikan antara mean tekanan darah sistolik dan diastolik sebelum dan sesudah intervensi.

Tabel 5

Perbedaan rata-rata tekanan darah sistolik dan diastolik sebelum dan sesudah intervensi pada kelompok kontrol

\begin{tabular}{cccccc}
\hline $\begin{array}{c}\text { Tekanan } \\
\text { Darah }\end{array}$ & Mean & SD & SE & N & $\begin{array}{c}p \\
\text { value }\end{array}$ \\
\hline a. $\begin{array}{l}\text { Sistolik } \\
\text { Pre test }\end{array}$ & 150,83 & 2,86 & 0,69 & 17 & 0,246 \\
$\quad$ Post test & 150,60 & 2,69 & 0,65 & 17 & \\
b. Diastolik & & & & & \\
$\quad$ Pre test & 92,71 & 1,53 & 0,37 & 17 & 0,681 \\
$\quad$ Post test & 92,80 & 1,43 & 0,34 & 17 & \\
\hline
\end{tabular}

Uji dependent pada kelompok kontrol diperoleh $p$ value sistol 0,246 $(p>\alpha)$. Kesimpulannya adalah bahwa tidak ada perbedaan yang signifikan antara mean tekanan darah sistolik pre test dan post test pada kelompok kontrol. Sedangkan untuk $p$ value diastolik adalah $0,681(p>\alpha)$. Ini berarti tidak ada perbedaan yang signifikan atara mean tekanan darah diastolik pre test dan post test pada kelompok kontrol. 
Tabel 6

Perbedaan rata-rata tekanan darah sistolik dan diastolik intervensi pada kelompok eksperimen dan kelompok kontrol

\begin{tabular}{lccccc}
\hline Variabel & Mean & SD & SE & N & p value \\
\hline Sistol & & & & & \\
Eksperimen & 145,44 & 3,60 & 0,87 & 17 & 0,000 \\
Kontrol & 150,60 & 2,69 & 0,65 & 17 & \\
\hline Diastol & & & & & \\
Eksperimen & 91,30 & 1,90 & 0,46 & 17 & 0,014 \\
Kontrol & 92,80 & 1,43 & 0,34 & 17 & \\
\hline
\end{tabular}

Uji statistik pada mean tekanan darah sistol diperoleh $p$ value $0,000(p<\alpha)$ dan mean tekanan darah diastol diperoleh $p$ value $0,014(p<\alpha)$. Hal ini menunjukkan bahwa ada pengaruh terapi refleksi APIYU terhadap tekanan darah pada penderita hipertensi.

\section{PEMBAHASAN}

Pengaruh terapi refleksi Alat Pijat Kayu (APIYU) dengan minyak zaitun terhadap tekanan darah pada pasien dengan hipertensi

Hasil penelitian dilakukan pada 34 responden yang dibagi menjadi 2 kelompok, yaitu kelompok eksperimen dan kelompok kontrol menemukan bahwa sebagian besar responden berada pada rentang usia 46-55 tahun sebanyak 55,9\%. Hasil ini didukung oleh penelitian Yumni (2018) menunjukkan hal yang sama bahwa pasien dengan hipertensi paling banyak berada pada rentang usia $>45$ tahun yaitu usia 40-50 tahun sebanyak 5 dan usia 51-59 tahun sebanyak 50\%. Tekanan darah seseorang akan meningkat bersamaan dengan bertambahnya umur, dikarenakan semakin berkurangnya distensibilitas dinding pembuluh darah. Hal ini mengakibatkan peningkatan tekanan sistolik dan diastolik (Syafrudin, 2011).

Jenis kelamin responden dalam penelitian ini mayoritas perempuan yaitu sebanyak 84,9\%. Hasil penelitian oleh Marisna (2017) menyatakan hal yang sama bahwa mayoritas jenis kelamin pada pasien dengan hipertensi sering terjadi pada perempuan yaitu sebanyak 80\% (12 responden). Hasil penelitian ini diperkuat oleh Rindang (2015) menyatakan bahwa lebih banyak responden yang berjenis kelamin perempuan sebanyak kelamin sebanyak 83,3\%. Hipertensi lebih banyak menyerang wanita setelah berumur 55 tahun, sekitar $60 \%$ penderita hipertensi adalah wanita. Hal ini disebabkan oleh perubahan hormone setelah menopause. Wanita pre menopause yang dilindungi oleh hormon estrogen yang berperan dalam meningkatkan kadar HDL (Cleese, 2010).

Mayoritas Indeks Masa Tubuh (IMT) responden dalam penelitian ini adalah normal yaitu sebanyak 94,1\%. IMT berkorelasi dengan tekanan darah, terutama tekanan darah sistolik. IMT dapat digunakan untuk menentukan seberapa besar seseorang tekena resiko penyakit tertentu yang disebabkan karena berat badannya (Syafrudin, 2011). Hasil penelitian Amalia (2018) menyatakan bahwa mayoritas IMT responden hipertensi dalam penelitiannya adalah berat badan normal yaitu sebanyak $61,5 \%$. 
Windy Enola Putri ${ }^{1}$, Wasisto Utomo ${ }^{2}$, Gamya Tri Utami ${ }^{3}$, Pengaruh Terapi Refleksi Alat Pijat Kayu (APIYU) dengan Minyak Zaitun terhadap Tekanan Darah pada Penderita Hipertensi

Sebagian besar tingkat pendidikan responden dalam penelitian ini adalah SMA yaitu sebanyak 55,9\%. Hasil penelitian ini diperkuat oleh Chanif dan Khoiriyah (2016) menyatakan bahwa mayoritas tingkat pendidikan dalam penelitian ini adalah SMA sebanyak $45,4 \%$.

Sebagian besar suku responden dalam penelitian ini adalah mayoritas suku Minang sebanyak 47,1\% (16 responden). Peneliti tidak menemukan penelitian tentang hubungan antara suku dengan kejadian hipertensi. Sebagian besar responden dalam penelitian adalah masyarakat bersuku.

Mayoritas status pekerjaan pada 34 responden menunjukkan bahwa sebanyak $82,4 \%$ tidak bekerja sedangkan responden yang bekerja sebanyak $17,6 \%$. Penelitian ini sejalan dengan penelitian oleh Anggara dan Prayitno (2013) bahwa ada hubungan antara tekanan darah dengan status pekerjaan dengan hasil $p$ value $0,000(p<\alpha)$. Orang yang tidak bekerja diasumsikan memiliki aktifitas fisik yang kurang aktif dibandingkan dengan orang yang bekerja. Aktifitas fisik sangat bermanfaat bagi kesehatan tubuh seseorang khususnya kesehatan untuk jantung (Prasetyaningrum, 2014).

Mayoritas responden dalam penelitian ini adalah tidak merokok sebanyak 100\%. Peneliti berasumsi bahwa orang yang tidak merokok lebih baik dibanding yang merokok. Merokok menyebabkan peninggian tekanan darah.
Rokok sangat berpengaruh yang dapat membahayakan jantung (Elsanti, 2009).

Mayoritas obat yang banyak dikonsumsi oleh responden dalam penelitian ini adalah obat amlodipine sebanyak 85,3\%. Peneliti tidak menemukan penelitian terkait yang membahas tentang hubungan obat yang dikonsumsi dengan kejadian hipertensi.

Waktu konsumsi obat pada 34 responden dengan hipertensi dalam penelitian ini adalah waktu konsumsi pada malam hari yaitu sebanyak 91,2\%. Sedangkan yang mengkonsumsi obat pada pagi hari yaitu sebanyak 8,8\%. Peneliti tidak menemukan penelitian terkait tentang hubungan antara waktu konsumsi obat dan durasi obat pada pasien hipertensi. Dalam penelitian ini waktu konsumsi obat yang sering dilakukan oleh pasien hipertensi yaitu pada malam hari sebelum tidur.

Hasil uji dependent didapatkan $p$ value tekanan darah sistol dan diastol pre test dan post test pada kelompok eksperimen 0,000 ( $p$ $<0,05)$. Hal ini berarti ada perbedaan yang signifikan antara mean tekanan darah sistol dan diastol pada kelompok eksperimen sebelum dan sesudah diberikan terapi refleksi APIYU dengan minyak zaitun.

Hasil penelitian ini sejalan dengan penelitian oleh Rezky, Hasneli dan Hasanah (2015) bahwa ada perbedaan yang signifikan antara mean tekanan darah sistolik dan diastolik sebelum dan sesudah intervensi dengan $p$ value $0,000(p<0,05)$, penelitian ini 
dilakukan pada jam yang sama, dimana peneliti telah menentukan waktu pengambilan data dari setiap responden yaitu jam 15.00 17.00 WIB yang menunjukkan bahwa pijat refleksi dapat menurunkan tekanan darah dan responden termasuk kategori hipertensi. Penelitian ini juga sejalan dengan penelitian oleh Marisna (2017) menyatakan bahwa terdapat perubahan tekanan darah sebelum dan sesudah dilakukan intervensi pijat refleksi kaki dengan $p$ value $0,000(p<0,05)$.

Hasil analisis menggunakan independent $t$ test mean tekanan darah sistol dan diastol post test pada kelompok eksperimen dan konrol yang tidak diberikan intervensi dapat disimpulkan bahwa ada pengaruh terapi refleksi APIYU dengan minyak zaitun terhadap tekanan darah pada penderita hipertensi. Hasil penelitian ini sejalan dengan penelitian oleh Rezky, Hasneli dan Hasanah (2015) didapatkan hasil hasil uji statistik mean tekanan darah post test pada kelompok eksperimen yang diberikan terapi pijat refleksi kaki didapatkan hasil bahwa ada pengaruh terapi pijat refleksi terhadap tekanan darah pada penderita hipertensi primer.

Terapi pijat refleksi adalah salah satu pengobatan terapi komplementer non farmakologis untuk menurunkan tekanan darah. Pengobatan hipertensi secara non farmakologi salah satunya adalah dengan melakukan terapi pijat refleksi pada kaki. Pemijatan dapat dilakukan dengan penekanan pada bagian tertentu dengan menggunakan jari atau alat bantu sehingga peredaran darah menjadi lancar (Hayuaji, 2016).

Pijatan pada kulit dan jaringan otot dapat menimbulkan rangsangan reseptor yang terletak di daerah tersebut. Kemudian impuls tersebut dihantarkan oleh saraf aferen menuju susunan saraf pusat dan kemudian susunan saraf pusat akan memberikan umpan balik dengan melepaskan asetilkolin dan histamine melalui impuls saraf eferen untuk merangsang tubuh bereaksi melalui mekanisme refleks vasodilatasi pembuluh darah yaitu dapat mengurangi aktivitas saraf simpatis dan meningktkan aktivitas saraf parasimpatis. Peningkatan dari saraf tersebut akan menimbulkan penurunan denyut jantung (heart rate) dan denyut nadi (pulse rate) sehinga menimbulkan respon relaksasi. Sedangkan pada penurunan saraf simpatis meningkatkan vasodilatasi arteriole dan vena yang mengakibatkan resistensi vascular perifer menurun, kemudian terjadinya penurunan pada tekanan darah (Marley, 2010; Sherwood, 2012).

Memijat daerah refleksi memberikan rangsangan yang diterima oleh saraf sensorik dan langsung disampaikan oleh saraf motorik kepada organ yang akan dikehendaki. Jika pijat refleksi di salah satu titik, maka tubuh akan melepaskan beberapa zat yaitu serotonin, histamine, bradikinin, Slow Reacting Substance (SRS) serta zat lain. Zat ini akan menyebabkan terjadinya dilatasi kapiler dan arteri serta dapat mengakibatkan terjadinya 
Windy Enola Putri ${ }^{1}$, Wasisto Utomo ${ }^{2}$, Gamya Tri Utami ${ }^{3}$, Pengaruh Terapi Refleksi Alat Pijat Kayu (APIYU) dengan Minyak Zaitun terhadap Tekanan Darah pada Penderita Hipertensi

perbaikan mikrosirkulasi pembuluh darah, sehingga mengakibatkan timbulnya efek relaksasi atau pelemasan otot-otot yang kaku serta akibat vasodilatasi umum dapat menurunkan tekanan darah secara stabil (Eni, 2012).

Rangsangan yang ditimbulkan terhadap reseptor saraf juga dapat mengakibatkan pembuluh darah menjadi melebar sehingga melancarkan aliran darah. Rangsangan yang diberikan dapat memperlancar aliran darah dan cairan dalam tubuh. Kemudian sirkulasi penyaluran nutrisi dan oksigen ke seluruh selsel tubuh menjadi lancar. Sirkulasi darah yang lancar akan memberikan suatu efek relaksasi dan kenyamanan pada seluruh anggota tubuh, sehingga tubuh akan mengalami kondisi yang seimbang (Aspiana, 2014).

\section{SIMPULAN}

Penelitian tentang terapi refleksi APIYU dengan minyak zaitun terhadap tekanan darah penderita hipertensi telah dilakukan dan menunjukkan hasil bahwa sebagian besar usia yang menderita hipertensi berada pada rentang usia 45-55 tahun sebanyak 55,9\%, mayoritas berjenis kelamin perempuan sebanyak $84,9 \%$, mayoritas tingkat pendidikan adalah tamatan SMA sebanyak $55,9 \%$, sebagian besar suku responden adalah suku Minang sebanyak 47,1\%, mayoritas status pekerjaan responden adalah tidak bekerja sebanyak $82,4 \%$, mayoritas obat yang digunkan yaitu amlodipine sebanyak 85,3\%, dan mayoritas waktu pemberian obat yaitu malam hari sebanyak $91,2 \%$.

Hasil uji statistik kelompok eksperimen dengan menggunakan uji $t$ dependent didapatkan $p$ value sistol 0,000 dan $p$ value diastol 0,000 $(p<0,05)$. Hal ini menunjukkan ada pengaruh terapi refleksi APIYU dengan minyak zaitun terhadap tekanan darah pada penderita hipertensi. Hasil uji statistik pada kelompok kontrol dengan menggunakan uji $t$ dependent diperoleh $p$ value sistol 0,246 ( $p>$ $\alpha)$ dan $p$ value diastol $0,681(p>\alpha)$. Hal ini menunjukkan tidak ada perbedaan yang signifikan antara mean tekanan darah sistolik pre test dan post test pada kelompok kontrol.

Hasil uji statistik uji independent diperoleh $p$ value mean tekanan darah sistol post test pada kelompok eksperimen dan kontrol yang tidak diintervensi yaitu $p$ value $0,000(p<0,05)$ dan mean tekanan darah diastol sesudah intervensi yaitu $p$ value 0,014 berarti $p$ value $<\alpha(0,05)$ artinya $\mathrm{H}_{0}$ ditolak. Dapat disimpulkan bahwa ada pengaruh terapi refleksi APIYU dengan minyak zaitun terhadap tekanan darah pada penderita hipertensi.

\section{SARAN}

Bagi Institusi Pendidikan Fakultas Keperawatan Hasil penelitian ini diharapkan dapat menjadi sumber informasi dalam pengembangan ilmu pengetahuan terutama tentang terapi non farmakologis yaitu terapi pijat refleksi APIYU dengan minyak zaitun 
terhadap tekanan darah pada penderita hipertensi untuk masa yang akan datang.

Bagi Masyarakat hasil penelitian ini dapat dijadikan sumber informasi bagi masyarakat khususnya penderita hipertensi mengenai pengobatan non farmakologis terapi pijat refleksi dengan menggunakan terapi komplementer dan diharapkan dapat dimanfaatkan secara aktif bagi penderita hipertensi.

Bagi Peneliti Lain hasil penelitian ini dapat dijadikan sebagai data, sumber data/informasi dasar, dan evidence based untuk melaksanakan penelitian lebih lanjut tentang hipertensi APIYU.

\section{DAFTAR PUSTAKA}

Alikin, A., Nuraeni, A., \& Supriyono, M. (2014). Pengaruh back message dengan aromaterapi lavender terhadap penurunan tekanan darah pada lansia hipertensi di Desa Kedungsari Kecamatan Ringinarum. Jurnal Ilmu Keperawatan dan Kebidanan.

Amalia, R. N. (2018). Efektifitas pijat refleksi kaki terhadap penurunan tekanan darah lansia hipertensi di PSTW budi luhur Yogyakarta.

Anies. (2018). Penyakit degeneratif: Mencegah \& mengatasi penyakit degeneratif dengan perilaku \& gaya hidup modern dan sehat. Yogyakarta: Ar-Ruzz Media.

Aspiana, N., \& Syaifudin. (2014). Pengaruh pijat refleksi kaki terhadap tekanan darah pada lansia hipertensi di PSTW Yogyakarta Unit Budi Luhur. STIKES 'Aisyiyah Yogyakarta.

Bagaskoro, S. (2012). Buku saku pijat untuk kesehatan, refleksi, akupressur, akupuntur.Yogyakarta: Pinang Merah.

Chanif, C., \& Khoiriyah, K. (2016). Penurunan tekanan darah pada pasien hipertensi berbasis Terapi pijat refleksi kaki. In Seminar Nasional Hasil Penelitian dan Pengabdian Masyarakat UNIMUS 2017. Muhammadiyah University Semarang.

Cleese, J. (2010). Tekanan darah tinggi. Klaten: Marshall.

Corwin, E. J. (2009). Patofisiologi: buku saku Edisi 3. Jakarta: EGC

Depkes RI. (2013). Riset kesehatan dasar. Jakarta: Badan Penelitian dan pengembangan Kesehatan Kementrian Kesehatan RI.

Eni, K. (2012). Pijat refleksi sebagai terapi komplementer keperawatan. Yogyakarta: Popup Design.

Hayuaji, G. R. (2016). Mahir pijat refleksi secepat kilat. Banguntapan Yogyakarta: Saufa.

Kamal, S., Widada, W., \& Kurniawan, H. (2016). Pengaruh terapi komplementer bekam dan minyak zaitun terhadap penurunan tekanan darah pada penderita hipertensi di wilayah kerja Puskesmas Lojejer Kecamatan Wuluhan Kabupaten Jember, n.d., 10.

Kurniawan. (2013). Hipertensi dan tekanan darah tinggi. Jakarta: Kanisius.

Marisna, D. (2017). Pengaruh terapi pijat refleksi kaki terhadap perubahan tekanan darah pada penderita hipertensi wilayah kerja Puskesmas Kampung Dalam Kecamatan Pontianak Timur. Jurnal ProNers, 3(1).

Martin, W., \& Mardian, P. (2016). Pengaruh terapi meditasi terhdap perubahan tekanan darah pada lansia yang mengalami hipertensi. Jurnal ipteks terapan.

Mills, C. J. (2012). A comparision of relaxation techniques on blood pressure reactivity and recovery assessing the moderating effect of anger coping style. Dissertation. Old Dominion University: http://search.proquest.com.

Nugroho, I. A., Asrin, \& Sarwono. 2012. Efektivitas pijat refleksi kaki dan hipnoterapi terhadap penurunan Kesehatan Keperawatan, http://www.academia.edu.

Prasetyaningrum, Y. I. (2014). Hipertensi bukan untuk ditakuti. Jakarta: FMedia. 
Windy Enola Putri ${ }^{1}$, Wasisto Utomo ${ }^{2}$, Gamya Tri Utami ${ }^{3}$, Pengaruh Terapi Refleksi Alat Pijat Kayu (APIYU) dengan Minyak Zaitun terhadap Tekanan Darah pada Penderita Hipertensi

Puskesmas Payung Sekaki. (2018). Profil puskesmas 10 penyakit tidak menular. Pekanbaru.

Putra, W. S. (2014). Sehat dengan terapi refleksi dan herbal di rumah sendiri. Yogyakarta: Katahati.

Rawasiah, A.B. (2014). Hubungan factor konsumsi makanan dengan kejadian hipertensi pada lanisa di Puskesmas Pattinggalongan, Makasar.

Rezky, R. A., Hasneli, Y., \& Hasanah, O. (2015). Pengaruh terapi pijat refleksi kaki terhadap tekanan darah pada penderita hipertensi primer. Jurnal Online Mahasiswa (JOM) Bidang Ilmu Keperawatan, 2(2), 14541462.

Safitri, P. (2009). Efektifitas massage kaki dengan minyak essensial lavender terhadap penurunan tekanan darah. Medan: PSIK FKep USU.

Setiadi. (2013). Konsep dan praktik penulisan riset keperawatan. Edisi ke-2. Yogyakarta: Graha Ilmu.

Sherwood, L. (2012). Fisiologi manusia dari sel ke sistem. Edisi 6. Jakarta: EGC

Wahyuni, S. (2014). Pijat refleksi untuk kesehatan. Jakarta Timur: Dunia Sehat.

Wirakusumah. (2013). Jus buah dan sayuran.Jakarta: PT Niaga Swadaya.

Yumni, F. L., \& Holidah, E. N. (2018). Masase kaki dengan citronella oil terhadap penurunan tekanan darah pasien hipertensi di wilayah Puskesmas Medokan Ayu Surabaya. Jurnal Keperawatan Muhammadiyah, 3(1). https://dspace.umkt.ac.id.

Zunaidi, A., Nurhayati, S., \& Prihatin, T. W. (2014). Pengaruh pijat refleksi terhadap tekanan darah pada penderita hipertensi di Klinik Sehat Hasta Therapetika Tugurejo Semarang. In Prosiding Seminar Nasional \& Internasional (Vol. 2, No. 1). https://jurnal.unimus.ac.id. 